BRITO, T.R. et al. Principais afecções que acometem bovinos pós-castração cirúrgica. PUBVET, Londrina, V. 5, N. 6, Ed. 153, Art. 1030, 2011.

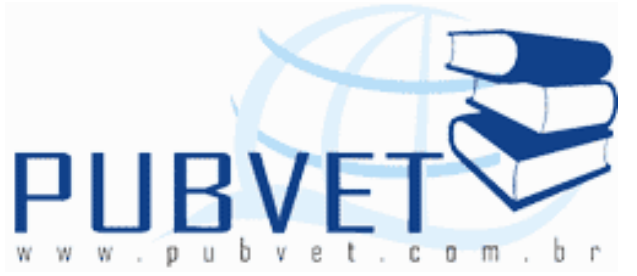

PUBVET, Publicações em Medicina Veterinária e Zootecnia.

\title{
Principais afecções que acometem bovinos pós-castração cirúrgica
}

Thalita Rocha Brito ${ }^{1}$, Mariela Silva Moura ${ }^{1}$, João Paulo Rodrigues Bueno ${ }^{1}$

Francisco Sales de Resende Carvalho ${ }^{2}$, Carlos Roberto Silva ${ }^{3}$

${ }^{1}$ Graduando em Medicina Veterinária, Universidade Federal de Uberlândia. Uberlândia, MG.

${ }^{2}$ Docente da Faculdade de Medicina Veterinária, Universidade Federal de Uberlândia. Uberlândia, MG.

${ }^{3}$ Médico Veterinário

*Autor para correspondência: Rua Ceará, s/n, Bloco 2D, CEP 38400-902, Uberlândia, MG, Brasil. E-mail: thata_rb@yahoo.com.br

\section{Resumo}

A castração dos bovinos é um método rotineiro na pecuária de corte, carcaças de animais castrados são de maior aceitação no mercado se comparada as dos animais inteiros. Objetivou-se com este estudo a avaliação das principais afeç̧ões pós-castração cirúrgica que acometem bovinos, principalmente o aparecimento de granulomas, abscessos, funiculites, miíase, hemorragias, óbitos e possíveis problemas na cicatrização, utilizando dois diferentes métodos cirúrgicos, incluindo o das duas incisões laterais na bolsa escrotal e o da ablação do ápice da bolsa escrotal. O estudo foi desenvolvido em duas propriedades distintas do município de Uberlândia, totalizando 229 animais, sendo 81 da Fazenda Pontal, mestiços, com idade entre 12 e 15 meses e peso 
BRITO, T.R. et al. Principais afecções que acometem bovinos pós-castração cirúrgica. PUBVET, Londrina, V. 5, N. 6, Ed. 153, Art. 1030, 2011.

médio de $245 \mathrm{~kg}$ os quais utilizou-se como método cirúrgico o da ablação do ápice da bolsa escrotal, e 148 provenientes da Fazenda Cruzeiro do Sul, mestiços, com idades entre 20 e 24 meses e peso médio de $350,25 \mathrm{~kg}$, sendo que, realizou-se nesta propriedade o método das duas incisões laterais como método cirúrgico de castração. A observação das afecções e o acompanhamento da evolução clínica da cicatrização dos animais foram realizados nos dias sete e vinte oito pós-castração. Concluiu-se que as principais afecções observadas na pós-castração cirúrgica foram miíase, abscesso, granuloma e hemorragia.

Palavras-chave: Bovino, Castração, Complicações pós-operatórias, Técnicas cirúrgicas

\title{
Major diseases affecting cattle post surgical castration
}

\begin{abstract}
The castration of beef cattle is a routine method, carcasses from intact animals are more acceptable in market than carcasses from castrated animals. The objective of this research is to evaluate the main problems that assault the cattle in post-operative period of castration, mainly appearance of granulomata, abscess, funiculitis, myiasis, hemorrhage, death and problems with the cicatrize using two different surgical methods including the two laterals incisions and the ablation of scrotum's apex. The study was performed in two different properties in municipal district of Uberlândia - MG, total of 229 animals, being 81 from Pontal farm, crossbreed, 12 to 15 age and average weight of $245 \mathrm{~kg}$ and 148 cattle from Cruzeiro do Sul farm, crossbreed, 20 to 24 age and with 350,25 average weight. The observation of these problems and the clinical evaluated of the cicatrization was done in the seventh and twenty eighth days post-castration. In conclusion, the mains problems observed post surgical castration are myiase, abscess, granulomata and hemorrhage.
\end{abstract}

Keywords: Castration, Cattle, Post-operative complications, Surgical Methods 
BRITO, T.R. et al. Principais afecções que acometem bovinos pós-castração cirúrgica. PUBVET, Londrina, V. 5, N. 6, Ed. 153, Art. 1030, 2011.

\section{Introdução}

Na economia nacional, a pecuária tem uma grande participação por ser um dos setores de maior importância do agronegócio. O Brasil atualmente detém o maior rebanho bovino comercial do mundo e possuem $20 \%$ de sua área agricultável coberta com pastagem, o que equivale a cerca de 185 milhões de hectares. Devido a este alto potencial de produção que sustenta, o país se firma como um dos maiores fornecedores de carne no mercado internacional. Mas apesar do potencial para a produção animal nos trópicos ser alto, a capacidade atual de produtividade ainda é baixa, representando apenas cerca de $50 \mathrm{~kg}$ de carne/ha/ano (CORSI, 1990).

A castração dos bovinos destinados ao abate é um método rotineiro na pecuária de corte, que tem como grande atrativo a facilidade de manejo, uma vez que torna os animais mais dóceis, eliminando alguns distúrbios indesejados da conduta sexual. Deve-se levar em conta a época ideal a se castrar os animais, que é aquela onde haja mais benefícios do que prejuízos, ou seja, uma relação custo: benefício favorável (FEIJó, 1997).

Os dias mais frios são mais apropriados tanto para o trabalho em si como para reduzir a incidência de moscas, porém dependendo da estação de monta utilizada na propriedade e da idade que se pretende castrar os animais, as épocas serão assim definidas (OLIVEIRA, SILVEIRA \& PEDRA, 2006). Ainda segundo este, a idade recomendada varia com a raça, o sistema de criação e plano nutricional adotado pelo produtor. Para animais que serão confinados ou semi-confinados o ideal é a partir dos 18 a 20 meses de idade até 24 meses.

Além das vantagens relacionadas à facilidade de manejo, destaca-se também a melhor aceitação de carcaças de animais castrados no mercado se comparada às dos animais inteiros por reduzir a incidência de cortes de carne escurecidos.

Por parte dos frigoríficos, há uma melhor aceitação pelas carcaças oriundas de animais castrados em relação aos não castrados, principalmente devido à presença da camada de gordura na carcaça dos primeiros, impedindo a alteração da cor da carne devido ao frio das câmaras. Ela é uma fração 
BRITO, T.R. et al. Principais afecções que acometem bovinos pós-castração cirúrgica. PUBVET, Londrina, V. 5, N. 6, Ed. 153, Art. 1030, 2011.

importante, pois influencia o aspecto visual da carcaça, a porção comestível e a qualidade da carne, além de servir como proteção (gordura subcutânea) contra a desidratação no resfriamento das carcaças (Moletta \& Restle, 1996).

A indústria frigorífica alega que animais inteiros tendem a produzir carne de baixo grau de qualidade, menos consistente, menor taxa de gordura intramuscular e com menor maciez.

Apesar das diversas vantagens desta técnica, deve-se estar atento aos diferentes problemas encontrados nos métodos de castração cirúrgica, os quais podem levar à perdas significativas de animais do rebanho em virtude de uma má manipulação cirúrgica ou até mesmo da escolha do momento para realizála.

A castração pode ser classificada em três grupos principais: castração física, química e hormonal. Esses grupos podem ser divididos pela técnica, mas no geral, a castração física é alcançada através da remoção dos testículos cirurgicamente, danificando-os irreversivelmente, ou levando-os a atrofia por estenose do vaso (AMERICAN VETERINARY MEDICAL ASSOCIATION'S ANIMAL WELFARE DIVISION, 2009).

Os métodos mais utilizados por trabalhadores das próprias propriedades são métodos cruentos os quais não incluem qualquer tipo de assepsia, na maioria dos casos. E, com isso, problemas indesejados pós-castração prejudicam os animais levando ao aparecimento de diversas afecções incluindo hemorragias, granulomas, funiculites, abscessos, e, principalmente ao aparecimento de mí́ases.

Desta forma, objetivou-se com este estudo identificar as principais afecções que acometem bovinos submetidos à castração cirúrgica em duas propriedades da região de Uberlândia, Minas Gerais. Foi levado em consideração o comportamento da evolução clínica da cicatrização durante as duas observações feitas no pós-cirúrgico. 
BRITO, T.R. et al. Principais afecções que acometem bovinos pós-castração cirúrgica. PUBVET, Londrina, V. 5, N. 6, Ed. 153, Art. 1030, 2011.

\section{Material e métodos}

O estudo desenvolveu-se em duas propriedades rurais do município de Uberlândia, no estado de Minas Gerais, entre os meses de março e abril de 2010.

Foram selecionados 229 bovinos machos e mestiços de duas propriedades do município de Uberlândia - MG, sendo 81 da Fazenda Pontal, com idade entre 12 e 15 meses e 148 da Fazenda Cruzeiro do Sul, com idade entre 20 e 24 meses.

Para realizar os dois procedimentos cirúrgicos, utilizou-se tronco de contenção e, na imobilização empregou-se madeira roliça de aproximadamente três metros de comprimento por dez centímetros de diâmetro, que foi mantida na altura do jarrete. Quando tracionada no sentido caudo-cranial, obrigava o animal a posicionar-se, ligeiramente, sentado e com os membros pélvicos suspensos. Essa posição facilitou a aproximação do cirurgião pela região posterior do animal. Os membros torácicos permaneceram apoiados ao solo, entretanto a cabeça foi elevada e desviada lateralmente, limitando os movimentos do animal (EURIDES, 1998).

Nas duas propriedades foram utilizados métodos distintos de castração cirúrgica, sendo que na Fazenda Pontal utilizou-se o método da ablação do ápice do escroto e, na Fazenda Cruzeiro do Sul, o método adotado foi o das duas incisões laterais.

O procedimento cirúrgico mais conhecido e adotado no presente estudo é o "método da faca" ou "canivete", através deste foram realizados os métodos de castração das duas incisões laterais e método da secção do ápice da bolsa escrotal, onde corta-se a túnica vaginal expondo assim o testículo. Logo em seguida, corta-se o ligamento da túnica vaginal que se insere na calda do epidídimo, liberando assim totalmente os testículos e o cordão espermático que são removidos sem seus invólucros. A hemostasia não é feita por meio de ligaduras, e sim pela tração do cordão espermático.

Após a intervenção cirúrgica, utilizaram-se medicamentos locais nos animais com $o$ intuito de evitar $o$ aparecimento de míases e, 
BRITO, T.R. et al. Principais afeç̧ões que acometem bovinos pós-castração cirúrgica. PUBVET, Londrina, V. 5, N. 6, Ed. 153, Art. 1030, 2011.

consequentemente, uma melhor cicatrização. Na Fazenda Cruzeiro do Sul utilizou-se o produto Tanidil (Bayer) e, na Fazenda Pontal, foi utilizado nos animais o produto Matabichiera azul (Valleé). Ainda se nas observações dos dias sete e vinte e oito pós-castração fosse observada algum tipo de afecção, estes medicamentos eram reutilizados nesses animais que apresentaram alterações cicatriciais.

O estudo baseou-se principalmente na observação das técnicas cirúrgicas realizadas por trabalhadores das próprias fazendas, não havendo intervenção de qualquer veterinário, com 0 intuito de concluir alguns resultados satisfatórios ou não por meio da observação dos meios. Dessa forma, notavase uma não higienização da bolsa testicular, a não utilização de qualquer método anestésico, a incisão era feita com o uso de canivetes em todos os animais e, raramente observava-se a utilização de luvas.

Após a castração dos bovinos, foram feitas as observações, palpações, análises clínicas e anotações sobre quaisquer alterações nos dias sete (D7) e vinte e oito (D28) do pós-cirúrgico. Analisou-se velocidade e qualidade da cicatrização, a presença ou não das seguintes alterações patológicas: granuloma, funiculite, miíase, abscessos ou hemorragias e até mesmo se houve óbito de algum animal.

\section{Resultados e Discussão}

Em ambos os métodos realizados os quais são os mais usados segundo Dietz et al. (1985); Stafforf \& Mellor (2005); Alves et al. (2007), foram observadas afecções diversas incluindo principalmente miíase, abscesso e granuloma.

A tabela 1 descreve a frequência de animais que adquiriram as diversas afeç̧ões no pós-cirúrgico nos diferentes dias de observação (D7 e D28) das duas propriedades. No método das duas incisões laterais, o índice de miíase foi bem menor quando comparado ao método da ablação do ápice da bolsa escrotal, correspondendo a 11 animais $(7,43 \%)$ na primeira e a 41 animais $(50,61 \%)$ na segunda. 
BRITO, T.R. et al. Principais afecções que acometem bovinos pós-castração cirúrgica. PUBVET, Londrina, V. 5, N. 6, Ed. 153, Art. 1030, 2011.

Tabela 1 - Frequência de animais acometidos por diferentes afecções no póscirúrgico de bovinos submetidos à castração, Uberlândia - MG, 2010.

\begin{tabular}{|c|c|c|c|c|c|c|}
\hline \multirow[t]{2}{*}{ Afecções } & \multicolumn{2}{|c|}{$\begin{array}{c}\text { Fazenda Cruzeiro } \\
\text { do Sul }\end{array}$} & \multirow[b]{2}{*}{$\begin{array}{l}\text { Total } \\
\text { (\%) }\end{array}$} & \multicolumn{2}{|c|}{$\begin{array}{c}\text { Fazenda } \\
\text { Pontal }\end{array}$} & \multirow[b]{2}{*}{$\begin{array}{r}\text { Total } \\
(\%) \\
\end{array}$} \\
\hline & D7 & $\mathrm{D} 28$ & & D7 & $\mathrm{D} 28$ & \\
\hline Hemorragia & - & - & - & $1,23 \%$ & - & $1,23 \%$ \\
\hline Miíase & $2,70 \%$ & $4,72 \%$ & $7,43 \%$ & $48,14 \%$ & $2,46 \%$ & $50,61 \%$ \\
\hline Abscesso & $0,67 \%$ & - & $0,67 \%$ & $12,34 \%$ & $1,23 \%$ & $13,58 \%$ \\
\hline Granuloma & $0,67 \%$ & - & $0,67 \%$ & $4,93 \%$ & $1,23 \%$ & $6,17 \%$ \\
\hline Funiculite & - & - & - & - & $1,23 \%$ & $1,23 \%$ \\
\hline
\end{tabular}

No método utilizado, conhecido como "método da faca" ou do "canivete", Moura; Luchiari Filho (1996) citam a probabilidade da ocorrência de infecções e miíases e ainda diz que o tempo de recuperação é mais longo o que pôde ser notado no presente trabalho.

De acordo com a evolução clínica da cicatrização, a intensidade das lesões foi diminuindo, mas em relação à ocorrência de miíases, na observação no D28 dos animais da Fazenda Cruzeiro do Sul, foi notado um aumento no índice de miíase $(4,72 \%)$ do que na observação no D7 $(2,70 \%)$ ao contrário da Fazenda Pontal, onde o índice de miíase no D7 foi de $48,14 \%$ caindo para $2,46 \%$ no D28, conforme o gráfico 1 .

O índice de abscesso na Fazenda Pontal foi superior ao da outra propriedade, correspondendo a 11 animais (13,58\%). No D28 desta mesma, apenas um animal apresentou abscesso, sendo que no D7 foram registrados 
BRITO, T.R. et al. Principais afecções que acometem bovinos pós-castração cirúrgica. PUBVET, Londrina, V. 5, N. 6, Ed. 153, Art. 1030, 2011.

10 animais com esta afecção. Já na outra propriedade, o índice de abscesso, assim como de granulomas foi mínimo, resultando em apenas um animal no D7 $(0,67 \%)$, como observado no gráfico1.

Já na Pontal, o índice de granulomas foi significativo, correspondendo à $6,17 \%$ (4 animais) no D7 e 1 animal no D28. Em relação à funiculite, esta foi a única a apresentar este tipo de afecção, um único animal no D28, como observado no gráfico 1 (um).

Em relação à hemorragia foi registrado um único óbito $(1,23 \%)$ na Fazenda Pontal no dia posterior à castração, não sendo observado mais em nenhum momento. Restle; Grassi; Feijó (1996) citam a morte de animais por hemorragia em conseqüência à castração cirúrgica, estando de acordo com o observado na Fazenda Pontal. Alves, et at. (2007) também descreve a hemorragia como uma intercorrência frequente nas castrações de bovinos, sendo essencial a hemostasia.

Gráfico1: Índices da ocorrência das principais afecções que acometeram bovinos na castração cirúrgica da Fazenda Pontal no município de Uberlândia MG,2010.

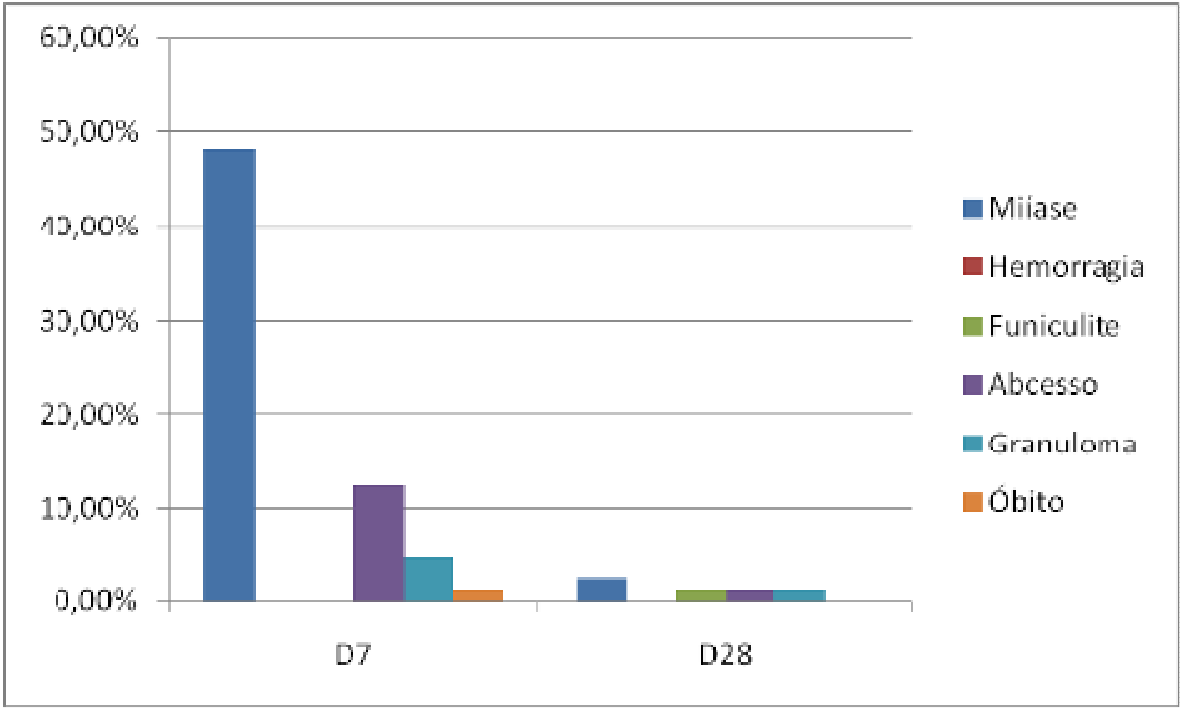


BRITO, T.R. et al. Principais afecções que acometem bovinos pós-castração cirúrgica. PUBVET, Londrina, V. 5, N. 6, Ed. 153, Art. 1030, 2011.

Gráfico 2: Índices da ocorrência das principais afecções que acometeram bovinos na castração cirúrgica da Fazenda Cruzeiro do Sul no município de Uberlândia - MG,2010.

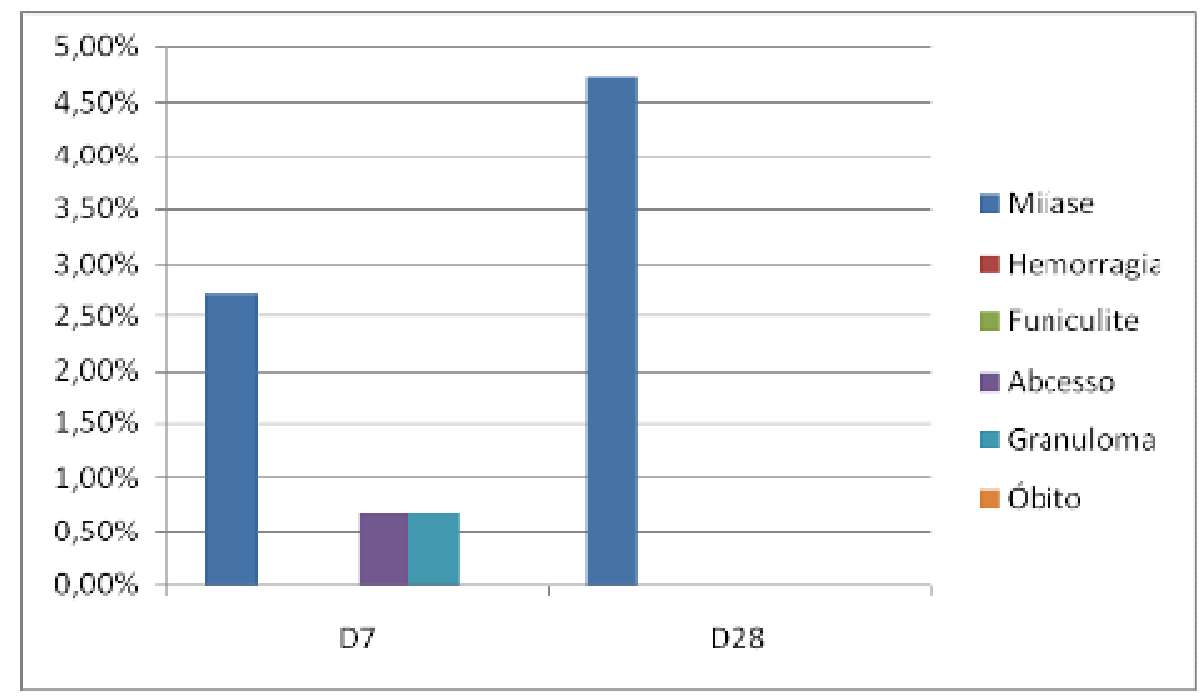

Dentre todas as afecções, as duas mais observadas no presente estudo incluem miíase e abscesso, estando de acordo com Silva et al (2001), que relata como as de maior ocorrência as citadas acima.

A não assepsia adequada no pré-cirúrgico pode ter agravado a ocorrência das afecções observadas no pós-operatório nesta pesquisa. Turner \& McIlwraith (2002) preconizam uma boa higiene durante o cirúrgico para um pós-operatório mais seguro.

Silva (2000) alega que o nível nutricional influencia a utilização da castração e diz ainda que, este procedimento é importante para animais abatidos tardiamente, pois favorece o manejo, a engorda e a qualidade. Isto foi observado em ambas às propriedades, onde a maioria dos animais estavam bem nutridos e, consequentemente responderam bem à técnica. Além disso, os animais da Fazenda Cruzeiro do Sul foram abatidos mais tardiamente. 
BRITO, T.R. et al. Principais afecções que acometem bovinos pós-castração cirúrgica. PUBVET, Londrina, V. 5, N. 6, Ed. 153, Art. 1030, 2011.

\section{Conclusão}

Conclui-se que, dentre todas as afecções observadas, as de maior prevalência foram miíase, abscesso e granuloma e, as de menor ocorrência incluíram hemorragia e funiculite, as quais acometeram um único animal.

$\mathrm{Na}$ Fazenda Pontal, $72,82 \%$ dos animais submetidos à castração cirúrgica, de alguma forma, apresentaram algum tipo de afecção no período pós cirúrgico, sendo observadas a mí́ase, abscesso, granuloma e um óbito em conseqüência de uma hemorragia.

Já na Fazenda Cruzeiro do Sul, este índice representou $8,77 \%$ e as afecções encontradas incluíram miíase, abscesso e granuloma.

\section{Referências}

ALVES, G. E. S; SANTOS, J. A. P. M; TANNUS, R.J; JANNUZZI, C. M. P. Aspectos fisiológicos e econômicos da castração em animais de produção e companhia: verdades e crendices. Revista do Conselho Federal de Medicina Veterinária, n. 40,2007, p. 67.

AVMA - American Veterinary Medical Associations`Animal Welfare Division. Welfare implications of castration of cattle. 2009. 7p. Disponível em

<http://www.avma.org/reference/backgrounders/castration_cattle_bgnd.pdf.> Acesso em: 25 out. 2009.

CAPUCILLE, D. J.; POORE, M. H.; ROGERS, G. M. Castration in cattle: Techniques and Animal Welfare Issues. Compendium continuing education for veterinarians, vol. 24, Philadelphia, v. 9, 2002, p. 66-73.

CHAVES, S. M.; SILVA, A. F. S.; MARTINS, M. E. P.; FIGUEREDO, E. J.; VIANA FILHO, P. R. L. ; VERÍSSIMO, A. C. C.; FIORAVANTI, M. C. S. Avaliação de uma técnica cirúrgica e três métodos de hemostasia na castração de machos bovinos. In: ENCONTRO DE INICIAÇÃO CIENTÍFICA E II DE PÓS-GRADUAÇÃO, 6., 2002, São José dos Campos. Anais ... São José dos Campos, v.1, 2002, p. 139-141.

CORSI, M. Produção e qualidade de forragens tropicais. In: CORSI, M.

Pastagens. Piracicaba, FEALQ: Sociedade Brasileira de Zootecnia, 1990, p. 69-85.

DIETZ, O; SCHAETZ, F; SCHLEITER, H; TEUSCHER, R. Operaciones y anestesia de los animales grandes y pequeños. 2. ed. Zaragoza: Acribia, 1985, p.800.

EURIDES, D. Métodos de contenção de bovinos. Guaíba: Editora Agropecuária, 1998, 78p.

FEIJÓ, G.L.D. Castração de bovinos de corte: a decisão é do produtor. Boletim informativo, CNPGC/ EMBRAPA. 1998. Disponível em : http:// <http://www.cnpgc.embrapa.br/publicacoes/divulga/GCD22.html> Acesso em: 20 mar. 2010. 
BRITO, T.R. et al. Principais afecções que acometem bovinos pós-castração cirúrgica. PUBVET, Londrina, V. 5, N. 6, Ed. 153, Art. 1030, 2011.

FEIJÓ, G. L. D. Castração de bovinos de corte: a decisão é do produtor. Empresa Brasileira de Pesquisa Agropecuária,CNPGC-MS, Campo Grande, Informe Técnico, n.22,1997, p. 64.

FIELD, R.A. Effect of castration on meat quality and quantity. Journal of Animal Science, Cambridge, v. 32, 1971, p. 849.

HICKMAN, J; WALKER, RG. Atlas de cirurgia veterinária. 2. ed. Rio de Janeiro: Guanabara, 1983, p. 63-72.

LAZZERI, L. Técnica operatória veterinária. Belo Horizonte: Gráfica da Escola de Veterinária da UFMG, 1994, p.415.

MOLETTA, J.L.; RESTLE, J. Características de carcaças de novilhos de diferentes grupos genéticos terminados em confinamento. Revista da Sociedade Brasileira de Zootecnia, Viçosa, v.25, n.5, 1996, p.876-888.

MOURA, A. C.; LUCHIARI FILHO, A. Castração. Pecuária de Corte, São Paulo, v. 6, n. 56, 1996, p. 45-47.

OliVeirA, V.A.; SILVEIRA, A.C.; PEDRA, A. Comunicação pessoal. 2006.

RESTLE, J.; GRASSI, C.; FEIJÓ, G. L. D. Características das carcaças e da carne de bovinos inteiros ou submetidos a duas formas de castração em condições de pastagens. Revista da Sociedade Brasileira de Zootecnia, Viçosa-MG, v. 25, n. 2, 2006, p. 334-343.

SILVA, F.F. Aspectos produtivos da castração de novilhos de corte. Caderno Técnico de Veterinária e Zootecnia, Belo Horizonte, v.33, 2000, p.68-94.

SILVA, L. A. F.; FILHO, P. R. L. V.; ALMEIDA, C. F.; RABELO, R. E.; FIORAVANTI, M. C. S.; EURIDES, D. Complicações pós-operatórias em bovinos submetidos a duas técnicas de orquiectomia. In: CONGRESSO BRASILEIRO DE BUIATRIA 4., 2001, Mato Grosso do Sul. Anais ... Campo Grande, 2001, p.140.

SILVA, L. A. F.; VIANA FILHO, P. R. L.; VERISSIMO, A. C. C.; SILVA, E. B.; SILVA, O. C; PÁDUA, J. T.; RABELO, R. E.; TRINDADE, B. R. SOUSA, J. N. Efeito da estação do ano, da idade, do método de contenção e da técnica cirúrgica na recuperação clínica e no ganho de peso de bovinos submetidos à orquiectomia. Revista Brasileira de Saúde e Produção Animal, Goiânia, v. 4, n.1, 2003, p. 18-29.

STAFFORD, K.J; MELLOR, D.J. The welfare significance of the castration of cattle: a review. New Zealand Veterinary Journal, New Zealand, v. 53, 2005, p .271-278.

TURNER, A. S.; MCILWAITH, C. W. Técnicas cirúrgicas em animais de grande porte. São Paulo: Editora Roca, 2002. 